NASA Technical Memorandum 106165

\title{
Dynamic Characteristics of Specialty Composite Structures With Embedded Damping Layers
}

D.A. Saravanos

Ohio Aerospace Institute

Brook Park, Ohio

and

C.C. Chamis

Lewis Research Center

Cleveland, Ohio

Prepared for the

Symposium on Vibroacoustic Characterization of Materials and Structures

sponsored by the American Society of Mechanical Engineers

Anaheim, California, November 8-12, 1992.

(NASA-TM-106165) DYNAMIC CHARACTERISTICS OF SPECIALTY COMPOSITE STRUCTURES WITH EMBEDDED DAMPING LAYERS (NASA) 32 p
N93-26705

Unclas 
$-1=$

$\ldots$

-




\title{
DYNAMIC CHARACTERISTICS OF SPECLALTY COMPOSITE STRUCTURES \\ WITH EMBEDDED DAMPING LAYERS
}

\author{
D.A. Saravanos ${ }^{*}$ \\ Ohio Aerospace Institute \\ 22800 Cedar Point Road \\ Brook Park, Ohio 44142 \\ and \\ C.C. Chamis \\ National Aeronautics and Space Administration \\ Lewis Research Center \\ Cleveland, Ohio 44135
}

\begin{abstract}
Damping mechanics for simulating the damped dynamic characteristics in specialty composite structures with compliant interlaminar damping layers are presented. Finiteelement based mechanics incorporating a discrete layer (or layer-wise) laminate damping theory are utilized to represent general laminate configurations in terms of lay-up and fiber orientation angles, cross-sectional thickness, shape and boundary conditions. Evaluations of the method with exact solutions and experimental data illustrate the accuracy of the method. Additional applications investigate the potential for significant damping enhancement in angle-ply composite laminates with cocured interlaminar damping layers.
\end{abstract}

\footnotetext{
"NASA Resident Research Associate at Lewis Research Center.
} 


\section{INTRODUCTION}

The passive damping capacity of polymer matrix composites is receiving current attention [1]. Composite materials are readily preferred in many flexible structures, where passive damping may significantly improve dynamic and acoustic performance. Previous research has shown, that composite materials can provide low but critical levels of damping $[2,3,4]$. Yet, due the inhomogeneity in properties and anisotropy through the thickness of laminated composites, additional enhancements of passive damping are possible from contributions of interlaminar shear damping in specialty composite laminates with embedded interlaminar damping layers $[5,6,7,8,9,10]$.

Most of the previously mentioned work has provided valuable insight to the damping of specialty composite laminate with damping layers, yet, it involves limitations which restrict applications to composite structures of general lay-up, geometry and boundary conditions. Consequently, this paper describes structural damping mechanics which enable the prediction of passive damping and other dynamic characteristics, such as, natural frequencies, mode shapes and transfer functions in specialty composite structures with embedded damping layers. The mechanics are generalized to include effects of general ply orientations, lay-ups, cross-sectional thickness, structural configurations and boundary conditions. A discrete layer damping theory (DLDT) is utilized with the capability to represent damping contributions from extension, flexure, flexure-shear coupling, and coupling from other possible asymmetries that may exist due to the heterogeneous nature of the laminate. A novel finite element based method incorporating DLDT is described and utilized to model the damped characteristics of composite structures of general thickness, shape, lamination, and boundary conditions. In this context, a four-node bilinear plate finite element is developed and described herein. 
Damping and natural frequency predictions are compared with both exact solutions for simply supported cross-ply composite plates [10], as well as, with experimental data for unsupported angle-ply plates to illustrate the quality and versatility of the damping mechanics. Additional evaluations and applications investigate the potential to enhance the material damping in angle-ply laminates and the associated trade-offs in stiffness and natural frequencies. Some of the results may be also used to establish guidelines for damping measurement and damping improvement in these specialty composite structures. 


\section{MECHANICS FOR COMPOSITE DAMPING}

The current section overviews the composite damping mechanics enabling the analysis of composite structures engineered for high passive damping.

\section{Composite Plies}

For a unidirectional composite loaded along the material axes, micromechanical models have been developed for the synthesis of elastic [11] and dissipative properties [12]. Five independent elastic parameters completely characterize the stiffness of a unidirectional composite (orthotropic but transversely isotropic material): in-plane longitudinal modulus $E_{111}$, transverse in-plane modulus $E_{122}$, in-plane Poisson's ratio $v_{112}$, in-plane shear modulus $G_{112}$, and interlaminar shear modulus $G_{123}$. Additionally, four independent damping loss factors characterize the composite damping, that is, longitudinal loss factor $\eta_{11}$ (direction 11), transverse in-plane damping $\eta_{12}$ (direction 22), transverse through-the-thickness damping $\eta_{13}=\eta_{12}$ (direction 33), in-plane shear damping $\eta_{16}$ (direction 12), interlaminar shear damping $\eta_{14}$ (direction 23), and interlaminar shear damping $\eta_{15}=\eta_{16}$ (direction 13). Both damping and elastic properties are explicitly related to fiber/matrix properties, and the fiber volume ratio (FVR).

For the case of off-axis composites, ie. composites loaded at an angle $\theta$, the stiffness matrix $\left[Q_{c}\right]$ and the damping matrix $\left[\eta_{c}\right]$ are provided respectively by the following transformations, [12]: 


$$
\begin{aligned}
& {\left[Q_{c}\right]=[R]^{-1}\left[Q_{l}\right][R]^{-T}} \\
& {\left[\eta_{c}\right]=[R]^{T}\left[\eta_{l}\right][R]^{-T}}
\end{aligned}
$$

where, $\left[Q_{1}\right]$ is the stiffness matrix of the composite in the material coordinate system, and $\left[\eta_{1}\right]$ represents the on-axis composite damping matrix. The transformation matrix $[R]$ and the matrices $\left[Q_{1}\right]$ and $\left[\eta_{1}\right]$ are shown in the Appendix. The matrices have the following general form:

$$
\left[Q_{c}\right]=\left[\begin{array}{cccccc}
Q_{c 11} & Q_{c 12} & 0 & 0 & 0 & Q_{c 16} \\
Q_{c 12} & Q_{c 22} & 0 & 0 & 0 & Q_{c 26} \\
0 & 0 & Q_{c 33} & 0 & 0 & 0 \\
0 & 0 & 0 & Q_{c 44} & Q_{c 45} & 0 \\
0 & 0 & 0 & Q_{c 45} & Q_{c 55} & 0 \\
Q_{c 16} & Q_{c 26} & 0 & 0 & 0 & Q_{c 66}
\end{array}\right]
$$

and

$$
\left[\eta_{c}\right]=\left[\begin{array}{cccccc}
\eta_{c 11} & \eta_{c 12} & 0 & 0 & 0 & \eta_{c 16} \\
\eta_{c 21} & \eta_{c 22} & 0 & 0 & 0 & \eta_{c 26} \\
0 & 0 & \eta_{c 33} & 0 & 0 & 0 \\
0 & 0 & 0 & \eta_{c 44} & \eta_{c 45} & 0 \\
0 & 0 & 0 & \eta_{c 54} & \eta_{c 55} & 0 \\
\eta_{c 61} & \eta_{c 62} & 0 & 0 & 0 & \eta_{c 66}
\end{array}\right]
$$

Assuming viscoelastic constituents, the viscoelastic law between generalized stresses and strains at the ply level may be eventually expressed by the following convolute product [13], 


$$
\sigma_{c}=[\tilde{Q}] * \epsilon_{c}=\int_{-\infty}^{t}[\tilde{Q}(t-\tau)] d \varepsilon(\tau)
$$

where ${ }^{*}$ indicates the convolution operation as defined above. The viscoelastic matrix $\left[Q_{c}\right]$ combines both stiffness and damping matrices. The relationship is more transparent in the frequency domain, where the complex stiffness matrix $\left[Q_{\mathrm{c}}^{*}\right]$ relates the amplitudes of stress and strain tensors as follows:

$$
\sigma_{c}(\omega)=\left[Q_{c}^{*}(\omega)\right] e_{c}(\omega)=\left(\left[Q_{c}\right]+i\left[Q_{c}\right]\left[\eta_{c}\right]\right) \epsilon_{c}(\omega)
$$

Hence, eqs. $(5,6)$ represent both elastic and damping properties of the composite. The case of viscous damping is a special case of eqs. $(5,6)$

\section{Interlaminar Layers}

The damping polymer in each interlaminar layer is assumed isotropic, therefore each interlaminar layer is treated as an isotropic ply which is a trivial case of the previously described mechanics. Two independent elastic properties (Young's modulus E and Shear Modulus $G$ ) and two independent damping properties (normal $\eta_{\mathrm{n}}$ and shear $\eta_{\mathrm{s}}$ loss factors) completely characterize their viscoelastic behavior at a given frequency and temperature. In this manner, all independent elastic and dissipative properties of the composite plies and interlaminar layers are considered.

\section{Laminate Damping}

In order to depart from the restrictions of simplified classical laminate mechanics and enable the modeling of special composite laminates including the effects of thicker sections, interlaminar inhomogeneity, and compliant interlaminar layers, a discrete layer laminate damping theory (DLDT) incorporating a piecewise continuous displacement 
field through-the-thickness is utilized [10]. Compared to other laminate theories based on assumed continuous displacement fields, the DLDT provided the capacity for more accurate strain and dissipative energy calculations in each ply, and particularly in each damping layer. The kinematic assumptions for the laminate theory are schematically shown in Fig 1b. In brief, the assumed displacement field has the form suggested by Barbero and Reddy [14]:

$$
\begin{aligned}
& u(x, y, z, t)=u^{o}(x, y, t)+\sum_{j=1}^{N} u^{j}(x, y, t) F^{j}(z) \\
& v(x, y, z, t)=v^{o}(x, y, t)+\sum_{j=1}^{N} v^{j}(x, y, t) F^{j}(z) \\
& w(x, y, z, t)=w^{o}(x, y, t)
\end{aligned}
$$

where, superscript $O$ represents the uniform through-the-thickness midplane deflection, and $u^{j}$ and $v^{j}$ are displacements, along the $x$ and $y$ directions respectively, at the interfaces between composite plies or sublaminates (group of plies) and the interlaminar damping layers. $\mathrm{F}^{\mathrm{j}}(\mathrm{z})$ are interpolation functions. In this manner, the assumed in-plane displacement field is general, in that it may represent extensional, flexural, shear, and coupled deformations, as well as, the interlaminar shear strains through-the-thickness of the laminate.

The laminate strains are directly derived from eqs. (5)

$$
\begin{array}{ll}
\epsilon_{c i}(x, y, z, t)=\epsilon_{c i}^{o}(x, y, t)+\sum_{j=1}^{N} \epsilon_{c i}^{j}(x, y, t) F^{j}(z) & i=1,2,6 \\
\epsilon_{c i}(x, y, z, t)=\epsilon_{c i}^{o}(x, y, t)+\sum_{j=1}^{N} \epsilon_{c i}^{j}(x, y, t) F_{z}^{j}(z) & i=4,5
\end{array}
$$

where, the midplane strains are, 


$$
\begin{array}{lll}
\epsilon_{c 1}^{0}=u_{x}^{0} & \epsilon_{c 2}^{0}=v_{y}^{0} & \epsilon_{c 6}^{0}=u_{y}^{0}+\nu_{x}^{0} \\
\epsilon_{c 4}^{0}=w_{y}^{0} & \epsilon_{c 5}^{0}=w_{x}^{0} &
\end{array}
$$

and the generalized strains are,

$$
\begin{aligned}
& \epsilon_{c 1}^{j}=u_{x}^{j} \quad \epsilon_{c 2}^{j}=v_{y}^{j} \quad \epsilon_{c 6}^{j}=u_{y}^{j}+v_{x}^{j} \\
& \epsilon_{c 4}^{j}=v^{j} \quad \epsilon_{c S}^{j}=u^{j}
\end{aligned}
$$

The comma in the subscripts indicates differentiation. Combination of eqs. (5) or (6) and (8) and integration through-the-thickness of the laminate provides the following generalized stress-strain relations in the time domain,

$$
\begin{aligned}
& N^{o}(t)=\int_{-h / 2}^{h / 2} \sigma d z=[\tilde{A}(t)] * e^{o}(t)+\sum_{m=1}^{N}\left[\tilde{B}^{m}(t)\right] * e^{m}(t) \\
& N^{j}(t)=\int_{-h / 2}^{h / 2} \sigma F^{j}(z) d z=\left[\tilde{B}^{j}(t)\right] * e^{o}(t)+\sum_{m=1}^{N}\left[\tilde{D}^{j m}(t)\right] * e^{m}(t), \quad j=1, \ldots, N
\end{aligned}
$$

where, $\left\{N^{\infty}\right\}$ and $\left\{N^{\dot{j}}\right\}$ are the generalized stresses. The equivalent laminate relations in the frequency domain are:

$$
\begin{aligned}
& N^{o}(\omega)=\left[A^{*}(\omega)\right] e^{o}(\omega)+\sum_{m=1}^{N}\left[B^{* m}(t)\right] e^{m}(\omega) \\
& N^{j}(\omega)=\left[B^{* j}(\omega)\right] e^{o}(\omega)+\sum_{m=1}^{N}\left[D^{* j m}(\omega)\right] e^{m}(\omega), \quad j=1, \ldots, N
\end{aligned}
$$

where, the complex laminate stiffness matrices include both elastic and damping matrices,

$$
\begin{aligned}
{\left[A^{*}\right] } & =[A]+i\left[A_{d}\right] \\
{\left[B^{* j}\right] } & =\left[B^{j}\right]+i\left[B_{d}^{j}\right] \\
{\left[D^{* j m}\right] } & =\left[D^{j m}\right]+i\left[D_{d}^{j m}\right]
\end{aligned}
$$

In the above equation, $\left[A_{d}\right]$ is the extensional laminate damping matrix, including out-of- 
plane shear terms, $\left[B_{d}{ }^{j}\right]$ are damping coupling matrices and $\left[D_{d}{ }^{j m}\right]$ are flexural/shear damping matrices. All damping matrix expressions in eq. (13) are given in the Appendix. Similarly, $[\mathrm{A}]$ is the extensional laminate stiffness matrix, $\left[\mathrm{B}^{\mathrm{j}}\right]$ are generalized coupling stiffness matrices, and $\left[D^{j \mathrm{~m}}\right]$ are the flexural/shear matrices given in the Appendix.

In this context, the dissipated strain energy per unit area of the laminate $\Delta w_{L}$, which is defined as,

$$
\Delta w_{L}=1 / 2 \int_{-h / 2}^{h / 2} 2 \pi \epsilon_{c}^{T}\left[Q_{c}\right]\left[\eta_{c}\right] \epsilon_{c} d z
$$

ultimately takes the form,

$$
\Delta w_{L}=1 / 2\left(\epsilon_{c}^{o T}\left[A_{d}\right] \epsilon_{c}^{o}+2 \epsilon_{c}^{o T} \sum_{j=1}^{N}\left[B_{d}^{j}\right] \epsilon_{c}^{j}+\sum_{j=1}^{N} \sum_{m=1}^{N} \epsilon_{c}^{j T}\left[D_{d}^{j m}\right] \epsilon_{c}^{m}\right)
$$

The maximum laminate strain energy per unit area $w_{L}$ is defined as,

$$
w_{L}=1 / 2 \int_{-h / 2}^{h / 2} \epsilon_{c}^{T}\left[Q_{c}\right] \epsilon_{c}
$$

and via combination of previous equations is also expressed as a separable form of material properties and strains,

$$
w_{L}=1 / 2\left(\epsilon_{c}^{o T}[A] \epsilon_{c}^{o}+2 \epsilon_{c}^{o T} \sum_{j=1}^{N}\left[B^{j}\right] \epsilon_{c}^{j}+\sum_{j=1}^{N} \sum_{m=1}^{N} \epsilon_{c}^{j T}\left[D^{j m}\right] \epsilon_{c}^{m}\right)
$$

In the above mechanics, the interlaminar compliant damping layers are considered as individual plies having isotropic elastic and damping matrices $\left[Q_{c}\right]$ and $\left[\eta_{c}\right]$ respectively. In this manner, the proposed laminate damping mechanics are general, as they can handle any composite material, number of composite plies, damping layers, and laminate lay-ups. 


\section{DYNAMIC ANALYSIS OF COMPOSITE STRUCTURES}

The developed computational mechanics for the damping analysis of composite structures with compliant layers, general laminations and shapes are summarized herein. The variational formulation of equilibrium equations for the candidate structure is as follows:

$$
-\int_{V} \delta e_{c}^{T} \sigma_{c} d V+\int_{V} \delta u^{T}(-\rho \ddot{u}) d V+\delta u_{i}^{T} F_{i}+\int_{S} \delta u_{s}^{T} F_{s} d s=0
$$

In view of the generalized laminate stress-strain relationships described in eqs. (12), the variational formulation in eq. (18) eventually takes the form:

$$
\begin{gathered}
-\int_{A}\left[\delta e^{o T} N^{o}+\sum_{j=1}^{N} \delta e^{j T} N^{j}\right\} d A-\int_{A}\left\{\delta u^{o T}\left[A_{m}\right] \ddot{u}^{o}+2 \delta u^{o T} \sum_{i=1}^{N}\left[B_{m}^{j}\right] \ddot{u}^{j}+\right. \\
\left.\sum_{j=1}^{N} \sum_{m=1}^{N} \delta u^{j T}\left[D_{m}^{j m}\right] \ddot{u}^{m}\right] d A+\delta u_{i}^{T} F_{i}+\int_{S} \delta u_{s}^{T} F_{s} d s=0
\end{gathered}
$$

The first left-hand integral in eq. (19) represents both stored and dissipated strain energies during a virtual displacement. The second left-hand integral represents the kinetic energy variation in the structure, where $\left[A_{m}\right],\left[B_{m}{ }^{j}\right]$ and $\left[D_{m}{ }^{j m}\right]$ are generalized laminate mass matrices described in the Appendix. The third and fourth left-hand terms in eq. (19) represent the virtual work of discrete forces and surface tractions, respectively.

The elastic laminate relations will result from eq. (19) if time effects are neglected in the first left-hand integral. The case of viscous damping is also a special case of eq. (19). In the frequency domain (harmonic vibration), eq. (19) results in equivalent expressions of complex laminate stiffness as described by eqs. (20) and (21) respectively.

The variational relationship is discretized to an approximate equivalent system of dynamic equations as follows: 


$$
\begin{aligned}
\left\{u^{0}, v^{0}, w^{0}\right\} & =\sum_{i=1}^{\text {nodes }}\left[\Phi_{i}\right]\left\{u_{i}^{0}, v_{i}^{o}, w_{i}^{o}\right\} \\
\left\{u^{j}, v^{j}\right\} & =\sum_{i=1}^{\text {nodes }}\left[\Phi_{i}\right]\left\{u_{i}^{j}, v_{i}^{j}\right\}, \quad j=1, \ldots, N
\end{aligned}
$$

where, subscript $i$ indicates the $i$-th node, and $\phi_{i}$ the interpolating function. The reference and generalized strain shape functions, $\left[\mathrm{R}^{\circ}\right]_{\mathrm{i}}$ and $[\mathrm{R}]_{\mathrm{i}}$ respectively, interpolating the strains to the nodal displacements, are obtained by differentiating eq. (20) in accordance with eqs. $(9,10)$. Then the damping or loss element matrix $\left[C_{e i j}\right]$ for nodes $i$ and $j$ takes the form:

$$
\left[C_{e j j}\right]=\int_{A}\left\{\begin{array}{cccc}
R_{i}^{o T}\left[A_{d}\right] R_{j}^{o} & R_{i}^{o T}\left[B_{d}^{1}\right] R_{j} & \ldots & R_{i}^{o T}\left[B_{d}^{N}\right] R_{j} \\
R_{i}^{T}\left[B_{d}^{1}\right] R_{j}^{0} & R_{i}^{T}\left[D_{d}^{j j}\right] R_{j} & \ldots & R_{i}^{T}\left[D_{d}^{1 N}\right] R_{j} \\
\cdot & \cdot & \ldots & \cdot \\
\cdot & \cdot & \ldots & \cdot \\
R_{i}^{T}\left[B_{d}^{N}\right] R_{i}^{0} & R_{i}^{T}\left[D_{d}^{N 1}\right] R_{j}^{0} & \ldots & R_{i}^{T}\left[D_{d}^{N N}\right] R_{j}
\end{array}\right] d A_{c}
$$

where $A_{e}$ is the area of the element. The stiffness and mass matrices of the element, $\left[\mathrm{K}_{\mathrm{ej}}\right]$ and $\left[\mathrm{M}_{\mathrm{eij}}\right]$ respectively, have analogous forms.

In this context, a bilinear four-node plate element was developed. The area integration in eq. (21) is performed numerically. However, selective reduced integration is used for both shear stiffness and damping terms to avoid overstiffening of the element in the case of low thicknesses. Such overstiffening was observed with full integration.

After the discretization, the system of dynamic equations has the following form in the frequency domain: 


$$
\omega^{2}[M]\{u]+i[C(\omega)]\{u\}+[K(\omega)]\{u\}=\{F(\omega)\}
$$

Viscous damping is a special case of the above equation, and results to the familiar dynamic system,

$$
[M]\{\ddot{u}\}+[C]\{\dot{u}\}+[K]\{u\}=\{F(t)\}
$$

Either one of eq. (22) or (23) may be solved directly to provide the transfer functions of the structure. The modal damping and natural frequencies of the structure may be directly obtained from the modal analysis of dynamic system (22). In a simpler form, however, the modal damping of the $\mathrm{n}$-th mode $\eta_{\mathrm{n}}$ can be expressed as the ratio of the dissipated over the maximum modal strain energy of the structure.

$$
\eta_{n}=\frac{1}{2 \pi} \frac{\Sigma \Delta W_{e j_{n}}}{\Sigma W_{e i j_{n}}}
$$

where, the dissipated and maximum stored strain energies of the element for the n-th mode are given by:

$$
\Delta W_{e i j_{n}}=1 / 2 \quad U_{i_{n}}^{T}\left[C_{e i j}\right] U_{j_{n}} \quad, \quad W_{e i j_{n}}=1 / 2 U_{i_{n}}^{T}\left[K_{e j j}\right] U_{j_{n}}
$$

The frequency effects on the damping and stiffness have been presently ignored, simply because efficient computation may require special solution techniques which are beyond the scope of this paper, that is, to analyze and quantify the effect of the composite material parameters on the structural dynamic characteristics. However, the frequency effects on fibers, matrix, and interphase layers may be incorporated with minimal effort, and this capability of the mechanics has been already demonstrated for the case of semianalytical plate solutions [10]. 


\section{APPLICATIONS AND DISCUSSION}

The developed computational mechanics were applied for the analysis of damping in various composite plates with embedded compliant interlaminar damping layers. The objectives of the case studies were: (1) to evaluate the quality of the method by correlating predictions with both analytical and experimental results; and (2) to explore and quantify the potential to improve the vibroacoustic characteristics of composite structures by embedding compliant layers between plies of strong interlaminar inhomogeneity. The second group of applications demonstrates the potential to engineer/tailor such specialty composite laminates for superior dynamic performance.

\section{Materials and Assumptions}

The selected materials were 0.60 FVR T300/934 composite, and ScotchDamp ISD110 damping film (3M Corp., St. Paul, MN) as interlaminar layers. The shear modulus and shear loss factor of the damping polymer were assumed $5.5 \mathrm{kpsi}$ and 0.16 respectively, and they represent average values of the polymer at $500 \mathrm{~Hz}$ and $30^{\circ} \mathrm{C}$ as provided by the manufacturer's data sheet. Due to non-existing data, the Young's modulus of the damping polymer was assumed $15.4 \mathrm{kpsi}$ (equivalent to Poisson's ratio of 0.3 ) and the normal loss factor was assumed to be negligible (0.016). Parametric studies have indicated strong insensitivity of modal damping and frequency to the dilatational properties of the damping polymer. Neither measured data for the damping of the T300/934 composite, nor for the 934 epoxy were available at the time of this report, therefore, the damping properties of the 934 epoxy were assumed equal to typical damping values of other epoxy matrices. Unless otherwise stated, the nominal thicknesses of the $\mathrm{Gr} / \mathrm{Ep}$ plies and damping layers were 0.0058 in $(0.15 \mathrm{~mm})$ and 0.005 in $(0.13 \mathrm{~mm})$, respectively. 


\section{Verification}

$\left[0 / \mathrm{i} / 90_{4}\right] \mathrm{s}$ Simply Supported Plate. The quality and accuracy of the developed structural damping mechanics were first investigated by comparisons with exact analytical solutions. Fig. 2 shows the modal damping and natural frequencies of a $28 \mathrm{~cm}$ by $28 \mathrm{~cm}$ (11 in by 11 in) $\left[0_{4} / / / 90_{4}\right] s$ simply supported plate predicted by the discrete finite element method and an exact plate solution previously developed based on DLDT [10]. Frequency effects were neglected in both solutions. The finite element analysis involved a 10 by 10 uniform mesh subdivision. As seen in Fig. 2, there is excellent agreement between the finite element based and exact damping predictions. The accuracy of the predictions is slightly but gradually reduced at higher modes, because the mesh is too coarse for representing the higher mode shapes. A more refined mesh would readily improve the predictions at higher modes.

To illustrate further the characteristic convergence of the element, the damping and natural frequencies of five mode shapes predicted with various mesh densities are plotted in Fig. 3. Both natural frequencies and modal damping have been normalized by the corresponding values of the exact solution. Clearly, both damping and frequency finite element predictions converge to the exact solution as the mesh is refined. Finally, as seen in Figs 2-3, the modal damping is typically overestimated by the discrete finite element model.

Angle-ply Unsupported Plates. The predicted dynamic characteristics of two symmetric angle-ply "free-free-free-free" square plates with compliant damping layers are also shown in Figs. 4 and 5. The laminate configurations were $\left[45_{2} /-45_{2} / \mathrm{i} / 45_{2} /-45_{2}\right]_{\mathrm{s}}$ and $\left[22.5_{2} /-\right.$ $\left.22.55_{2} / \mathrm{i} / 22.5_{2} /-22.5_{2}\right]_{\mathrm{s}}$ respectively. In-house experimentally measured damping values and 
natural frequencies for these plates in a "unsupported" configuration [15] are also shown in these figures. The composite plates were fabricated in-house by hand lay-up, cocured at $350^{\circ} \mathrm{F}\left(175^{\circ} \mathrm{C}\right)$ and $50 \mathrm{psi}(345 \mathrm{KPa})$, and finally cut to $28 \mathrm{~cm}$ by $28 \mathrm{~cm}$ (11 in by $11 \mathrm{in})$.

In both cases, the correlation between measured and predicted modal damping and corresponding natural frequencies of the damped plates appears very good, especially in the lower frequency regime. There is an overestimation of damping at higher modes which can be attributed to the insufficient mesh density and/or the omission of frequency effects. A more refined mesh and the inclusion the gradual damping reduction in ISD110 polymer at higher frequencies will reduce the overestimation. The inclusion of frequency effects in the model is planned as future research.

Predicted and measured results for composite plates of identical laminations but without damping layers are also shown in Figs. 4 and 5. It is pointed out, that the sole purpose of plotting the results for the undamped plates is for demonstrating only approximately the attained improvements in modal damping values when the damping layers are embedded. At this point the predicted and measured results for the undamped plates cannot be correlated, since measured damping data for the T300/934 epoxy system were not available at the time of this paper, and the predictions were based on assumed values.

\section{Damping Enhancement in Angle-Ply Laminates}

The predicted loss factors and corresponding natural frequencies of the first five modes of two simply-supported plates, with laminations $\left[\theta_{2} /-\theta_{2} / \mathrm{i} / \theta_{2} /-\theta_{2}\right]_{s}$ and $\left[\theta_{2} /-\theta_{2} / \mathrm{i} /-\theta_{2} /+\theta_{2}\right]_{s}$ respectively, are shown in Figs. 6-10 as functions of the ply angle $\theta$. The modal loss factors and natural frequencies of plates with identical geometrical and laminate 
configurations, but without damping layers (undamped), that is $\left[\theta_{2} /-\theta_{2} / \theta_{2} /-\theta_{2}\right]_{\mathrm{s}}$ and $\left[\theta_{2} /-\right.$ $\left.\theta_{2} /-\theta_{2} /+\theta_{2}\right]_{s}$ respectively, are also plotted in the same Figures.

Clearly, the addition of the damping layers drastically improved the damping capacity of the composite plates. Most importantly, the predicted results demonstrate the potential for enhancing the damping of the composite structure by altering the fiber orientation angle. For most modes the maximum damping occurred consistently at $\theta=45^{\circ}$. Indeed in the considered laminate configurations, non-zero ply angles alter the anisotropy of the restraining sublaminates, induce additional coupling terms in their stiffness matrices and increase the through-the-thickness inhomogeneity of the laminate. Consequently, higher interlaminar shear stresses are developed in the damping layer to maintain the stress equilibrium, which increase the damping contributions of the damping layers. This damping enhancement is further signified by the observation that the predicted damping of the composite plates without damping layers is typically reduced for ply angles between $0^{\circ}$ and $90^{\circ}$. Finally, the damped plates exhibit similar or higher natural frequencies than the undamped plates between 0 and 90 degs., hence, this enhancement of damping does not seem to reduce the natural frequencies and stiffness.

As seen in Figs. 6-10, the improvements in the damping are increased at higher modes, for example mode $1(1,1)$, mode $2(1,2)$, mode $3(1,3)$, and mode $5(2,2)$. The numbers in parenthesis indicate the mode order at $\theta=0$ degs. The uneven damping increases for various mode shapes indicate the interrelation between laminate configuration and mode shape. A significant part of the damping improvements were induced by altering the anisotropy in the restraining composite sublaminates. It seems though, that alternating fiber orientations in the plies which contain the damping layer produce some additional damping improvements. It is also interesting to note, that not all modes exhibited potential for damping improvements with off-axis plies. This is illustrated in mode 4 , 
which corresponds to mode shape $(2,1)$ at $0^{\circ}$, and exhibits its higher damping at $\theta=0$ degs, that is, when the outer restraining sublaminates have the higher flexural stiffness in the direction of the flexure.

The presented results, illustrated the accuracy and versatility of the structural damping mechanics in predicting the damped dynamic characteristics of specialty composite structures with cocured interlaminar damping layers. The applications have demonstrated the potential to develop "engineered" composite laminates with embedded interlaminar damping layers which are capable of providing higher and tailorable damping than traditional isotropic materials. The results finally demonstrate the existing opportunity to tailor such composite structures for improved dynamic characteristics in terms of damping and natural frequencies.

\section{SUMMARY}

Damping mechanics for the analysis of damping in specialty composite structures incorporating damping layers were developed and presented. Novel finite-element based mechanics incorporating a discrete layer damping theory (or layer-wise damping mechanics) were developed for predicting the damped characteristics of composite structures with embedded compliant interlaminar layers of general thickness, shape, lamination, and boundary conditions.

Comparisons with exact solutions and experimental data illustrated the quality and accuracy of the structural damping mechanics. Case studies with interlaminar damping layers embedded into angle-ply composite laminates demonstrated that such angle-ply composite laminates and structures can combine higher and tailorable damping together 
with improved dynamic characteristics.

\section{ACKNOWLEDGEMENT}

The work was supported by NASA Grant NCC3-208/4. This support is gratefully acknowledged. The authors want also to thank $3 \mathrm{M}$ Corporation for providing samples of the damping polymer.

\section{REFERENCES}

1. Venneri S. L., and Noor A.K., "Overview and Major Characteristics of Future Aeronautical and Space Systems", ALAA-92-2441-CP, Proceedings, 33rd ALAA/ASME/ASCE/AHS/ASC Structures, Structural Dynamics, and Materials Conference, Dallas, TX, April 13-15, 1992, pp. 1924-1934.

2. Schultz, A. B. and Tsai, S. W., "Measurements of Complex Dynamic Moduli for Laminated Fiber-Reinforced Composites," Joumal of Composite Materials, Vol. 3, July 1969 , pp. 434-443.

3. Adams, R. D. and Bacon, D. G. C., "Effect of Fibre Orientation and Laminate Geometry on the Dynamic Properties of CFRP," Journal of Composite Materials, Vol. 7, Oct. 1973, pp. 402-428.

4. Saravanos D. A. and Chamis C. C., "Mechanics of Damping for Fiber Composite Laminates Including Hygro-Thermal Effects," ALAA Journal, Vol. 28, No. 10, Oct. 1990, pp. 1813-1819.

5. Chen G. S. and Wada B. K., "Passive Damping for Space Truss Structures," 29th Structures, Structural Dynamics and Materials Conference, 29th, Pt. 3, AIAA, 1988, pp. 1742-1749.

6. Bronowicki A. J. and Diaz H. P., "Analysis, Optimization, Fabrication and Test of Composite Shells with Embedded Viscoelastic Layers," Proceedings of Damping '89, Wright-Paterson AFB, OH, Report WRDC-TR-89-3116-Vol-1, 1989, Sec. GC, 
paper GCA. Viscoelastic Tape Lengths for Maximizing Damping in Laminated Composites," Proceedings of Damping '89, Wright-Paterson AFB, OH, Report WRDC-TR-893116-Vol-1, 1989, Sec. IA, paper IAB.

8. Rao V. S., Sun C. T. and Sankar B. V., "Damping and Vibration Control of Some Laminated Composite Beams Using Add-On Viscoelastic Materials," Proceedings of Damping '89, Wright-Paterson AFB, OH, Report WRDC-TR-89-3116-Vol-2, 1989, Sec. VA, paper VAA.

9. Barrett D. J., "An Anisotropic Laminated Damped Plate Theory," Naval Air Development Center, Warminster, PA, Report No. NADC-90066-60, July, 1990.

10. Saravanos, D. A. and Pereira J. M., "Effects of Interply Damping Layers on the Dynamic response of Composite Plates," ALAA Joumal, in press; (also, AIAA Paper 91-1124-CP, 32nd AIAA Structures, Structural Dynamics, and Materials Conference, Baltimore, MA, Apr. 8-10, 1991).

11. Murthy, P. L. N. and Chamis, C. C., "ICAN: Integrated Composite Analyzer," ALAA Paper 84-0974, May 1984.

12. Saravanos D. A. and Chamis C. C. "Unified Micromechanics of Damping for Unidirectional Fiber Composites," Joumal of Composites Technology and Research, Vol. 12, No. 1, 1990, pp. 31-40.

13. Christensen R. M., Theory of Viscoelasticity: An Introduction, Academic Press Inc., 1971, New York.

14. Barbero E. J., Reddy J. N. and Teply J., "An Accurate Determination of Stresses in Thick Composite Laminates Using a Generalized Plate Theory," Int. Journal for Numerical Methods in Engineering, Vol. 29, Jan. 1990, pp. 1-14.

15. Pereira M. J., "Dynamic Response of Composite Plates with Interlaminar Damping Layers," Proceedings, Symposium on Vibroacoustic Characterization of Materials and Structures, ASME Winter Annual Meeting, Anaheim, California, Nov. 8-13, 1992 


\section{APPENDIX}

On axis ply stiffness matrix $\left[Q_{1}\right]$ of a transversely isotropic composite

$$
[Q]=\left[\begin{array}{cccccc}
Q_{I 11} & Q_{112} & 0 & 0 & 0 & 0 \\
Q_{I I 2} & Q_{122} & 0 & 0 & 0 & 0 \\
0 & 0 & Q_{133} & 0 & 0 & 0 \\
0 & 0 & 0 & Q_{I M} & 0 & 0 \\
0 & 0 & 0 & 0 & Q_{I S 5} & 0 \\
0 & 0 & 0 & 0 & 0 & Q_{166}
\end{array}\right]
$$

where

$$
\begin{array}{lllc}
Q_{111}= & E_{111} / \Delta & Q_{112}= & v_{112} E_{122} / \Delta \\
Q_{122}= & E_{122} / \Delta & Q_{133}= & E_{133} \\
Q_{111}= & G_{123} & Q_{155}= & G_{113} \\
Q_{166}= & G_{112} & \Delta= & 1-v_{112} v_{101}
\end{array}
$$

Transformation matrices:

$$
\begin{aligned}
& {[R]=\left[\begin{array}{cccccc}
m^{2} & n^{2} & 0 & 0 & 0 & 2 m n \\
n^{2} & m^{2} & 0 & 0 & 0 & -2 m n \\
0 & 0 & 1 & 0 & 0 & 0 \\
0 & 0 & 0 & m & -n & 0 \\
0 & 0 & 0 & n & m & 0 \\
-m n & m n & 0 & 0 & 0 & m^{2}-n^{2}
\end{array}\right], \quad m=\cos \theta, \quad n=\sin \theta} \\
& {[R]^{-1}=[R(-\theta)]}
\end{aligned}
$$

On-axis damping matrix: 
$\left[\eta_{l}\right]=\operatorname{diag}\left\{\eta_{l 1}, \eta_{l 2}, \eta_{l 3}, \eta_{l 4}, \eta_{l 5}, \eta_{l 6}\right\}$

Generalized damping matrices

$$
\begin{array}{rlr}
{\left[A_{d}\right]} & =2 \pi \sum_{k=1}^{N_{1}} \int_{h_{\mathrm{k}-1}}^{h_{k}}\left[E_{c}\right]_{k}\left[\eta_{c}\right]_{k} d z & \\
\left(B_{d}^{j}\right)_{i n} & =2 \pi \sum_{k=1}^{N_{1}} \int_{h_{\mathrm{k}-1}}^{h_{k}}\left(\left[E_{c}\right]_{k}\left[\eta_{c}\right]_{k}\right)_{i n} F^{j}(z) d z & \\
\left(B_{d}^{j}\right)_{i n} & =2 \pi \sum_{k=1}^{N_{1}} \int_{h_{\mathrm{k}-1}}^{h_{k}}\left(\left[E_{c}\right]_{k}\left[\eta_{c}\right]_{k}\right)_{i n} F_{z}^{j}(z) d z=1,2,6 \\
\left(D_{d}^{j m}\right)_{i n} & =2 \pi \sum_{k=1}^{N_{1}} \int_{h_{\mathrm{k}-1}}^{h_{k}}\left(\left[E_{c}\right]_{k}\left[\eta_{c}\right]_{k}\right)_{i n} F^{j}(z) F^{m}(z) d z & \\
\left(D_{d}^{j m}\right)_{i n} & =2 \pi \sum_{k=1}^{N_{1}} \int_{h_{\mathrm{k}-1}}^{h_{k}}\left(\left[E_{c}\right]_{k}\left[\eta_{c}\right]_{k}\right)_{i n} F_{z}^{j}(z) F_{z}^{m}(z) d z & i, n=1,2,6
\end{array}
$$

Generalized stiffness matrices

$$
\begin{array}{rlr}
{[A]} & =\sum_{k=1}^{N_{1}} \int_{h_{\mathrm{k}-1}}^{h_{\mathrm{k}}}\left[E_{c}\right]_{k} d z & \\
\left(B^{j}\right)_{\text {in }} & =\sum_{k=1}^{N_{1}} \int_{h_{\mathrm{k}-1}}^{h_{\mathrm{k}}}\left(\left[E_{c}\right]_{k}\right)_{i n} F^{j}(z) d z & i, n=1,2,6 \\
\left(B^{j}\right)_{\text {in }} & =\sum_{k=1}^{N_{1}} \int_{h_{\mathrm{k}-1}}^{h_{\mathrm{k}}}\left(\left[E_{c}\right]_{k}\right)_{i n} F_{z}^{j}(z) d z & \\
\left(D^{j m}\right)_{\text {in }} & =\sum_{k=1}^{N_{1}} \int_{h_{\mathrm{k}-1}}^{h_{\mathrm{k}}}\left(\left[E_{c}\right]_{k}\right)_{i n F^{j}} F^{j}(z) F^{m}(z) d z & \\
\left(D^{j m}\right)_{i n} & =\sum_{k=1}^{N_{1}} \int_{h_{\mathrm{k}-1}}^{h_{\mathrm{k}}}\left(\left[E_{c}\right]_{k}\right)_{i n} F_{z}^{j}(z) F_{z}^{m}(z) d z &
\end{array}
$$

Generalized mass matrices 


$$
\begin{aligned}
& {\left[A_{m}\right]=\sum_{k=1}^{N_{1}} \int_{h_{\mathrm{k}-1}}^{h_{\mathrm{k}}}[\operatorname{diag}(\rho)]_{k} d z} \\
& {\left[B_{m}^{j}\right]=\sum_{k=1}^{N_{1}} \int_{h_{\mathrm{k}-1}}^{h_{\mathrm{k}}}[\operatorname{diag}(\rho)]_{k} F^{j}(z) d z} \\
& {\left[D_{m}^{j m}\right]=\sum_{k=1}^{N_{1}} \int_{h_{\mathrm{k}-1}}^{h_{\mathrm{k}}}[\operatorname{diag}(\rho)]_{k} F^{j}(z) F^{m}(z) d z}
\end{aligned}
$$




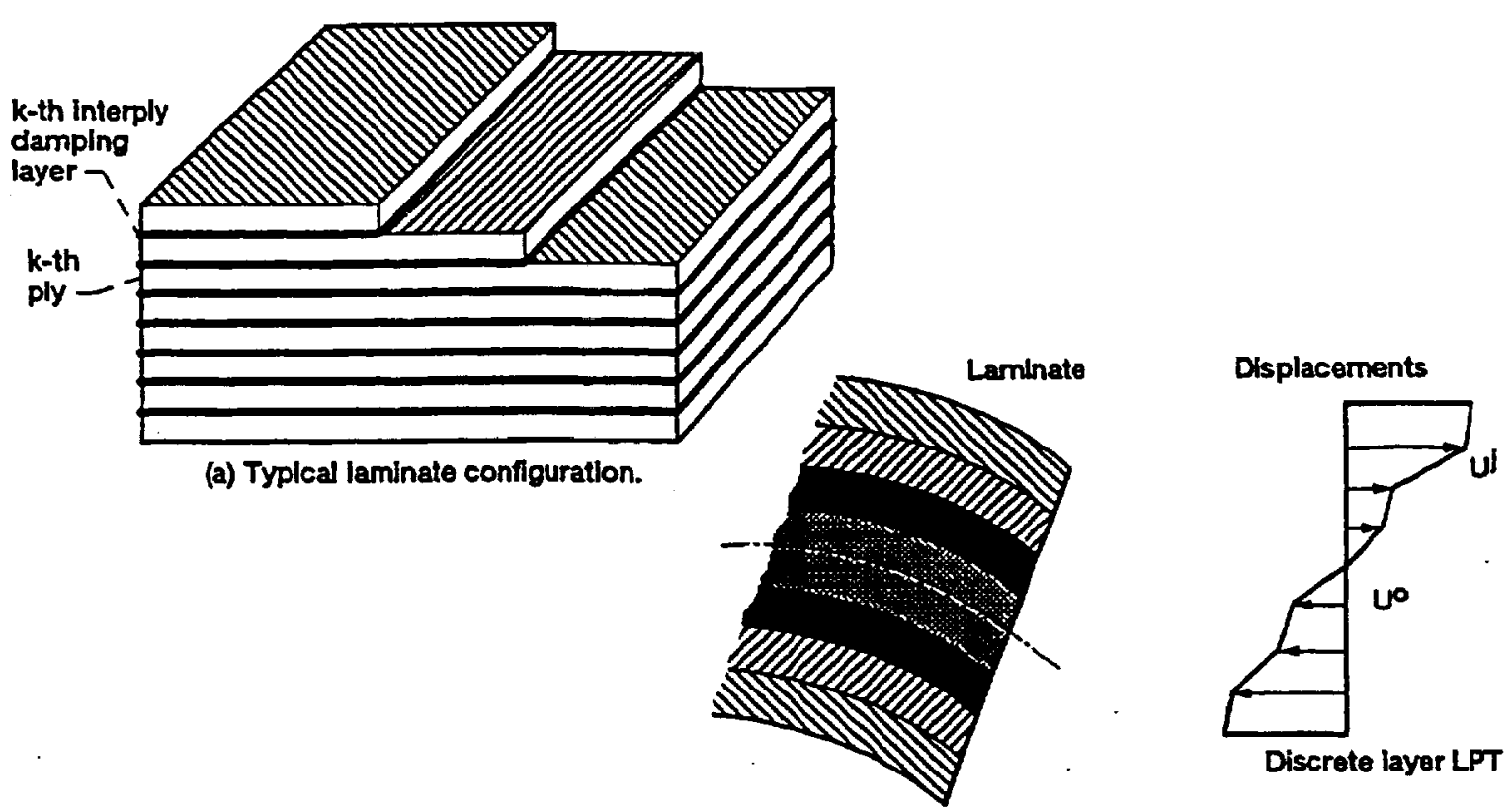

(b) Kinematic assumptions of discrete layer laminate theory.

Figure 1 Specialty laminates with interlaminar damping layers. (a) Typical laminate configuration; (b) Kinematic assumptions of discrete layer laminate theory.

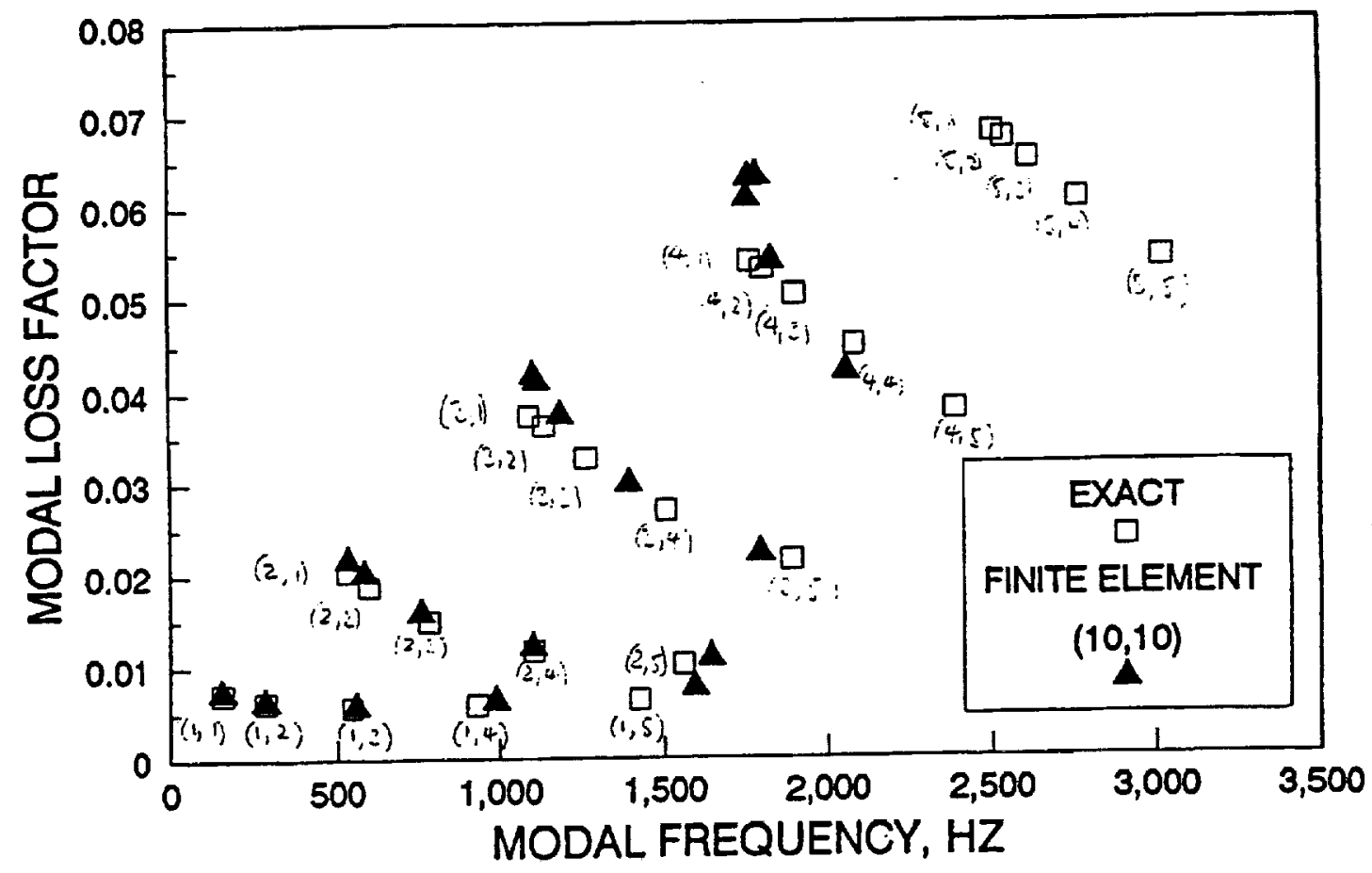

Figure 2 Modal characteristics of a $\left(0_{4} / \mathrm{i} / 90_{4}\right)$ s T300/934 simply supported plate with ISD110 damping layers. Numbers in parenthesis indicate mode order of exact solution. 

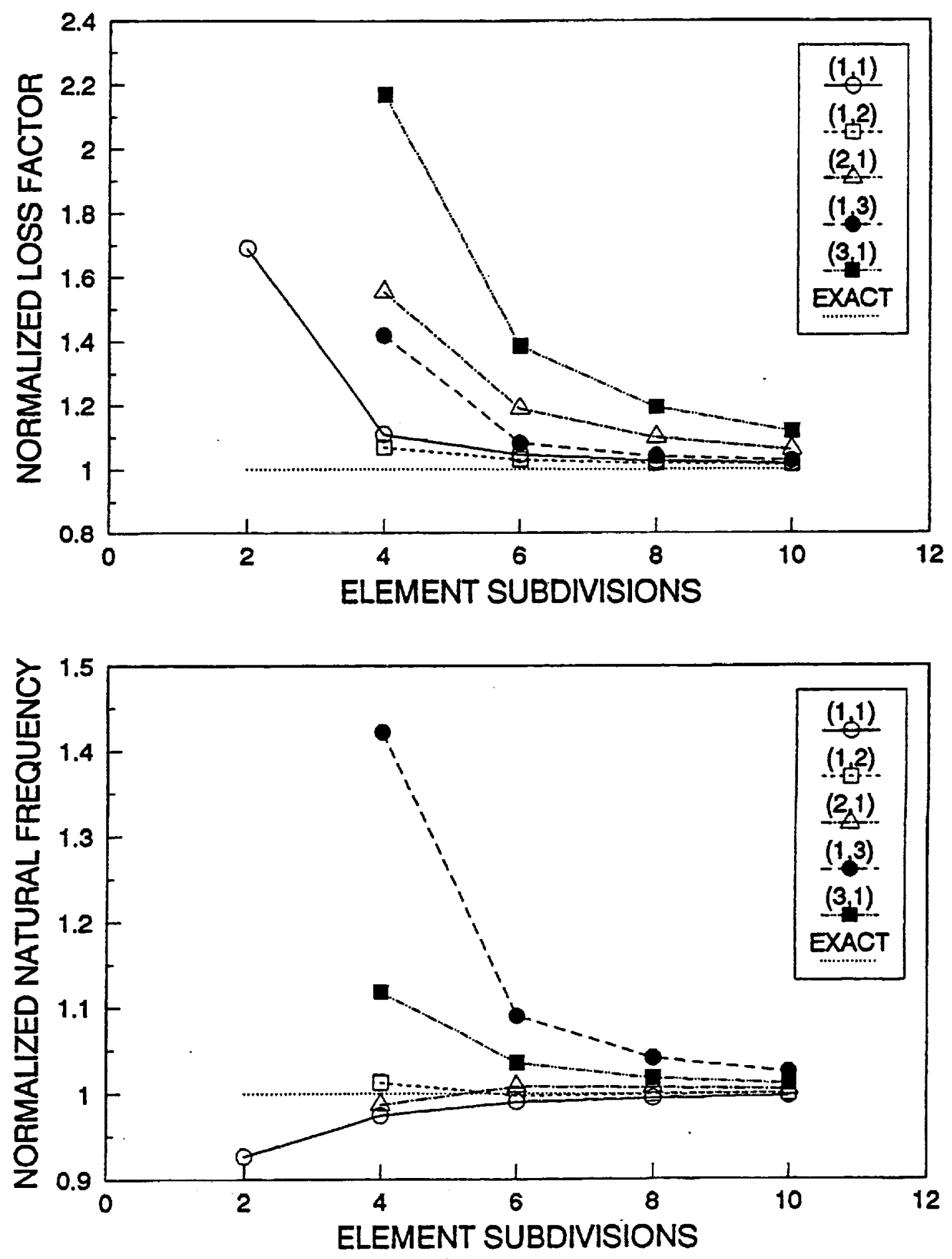

Figure 3 The effect of mesh density on the modal characteristics of a $\left[0_{4} / \mathrm{i} / 90_{4}\right]_{3}$ T300/934 simply supported plate with ISD110 damping layers. 


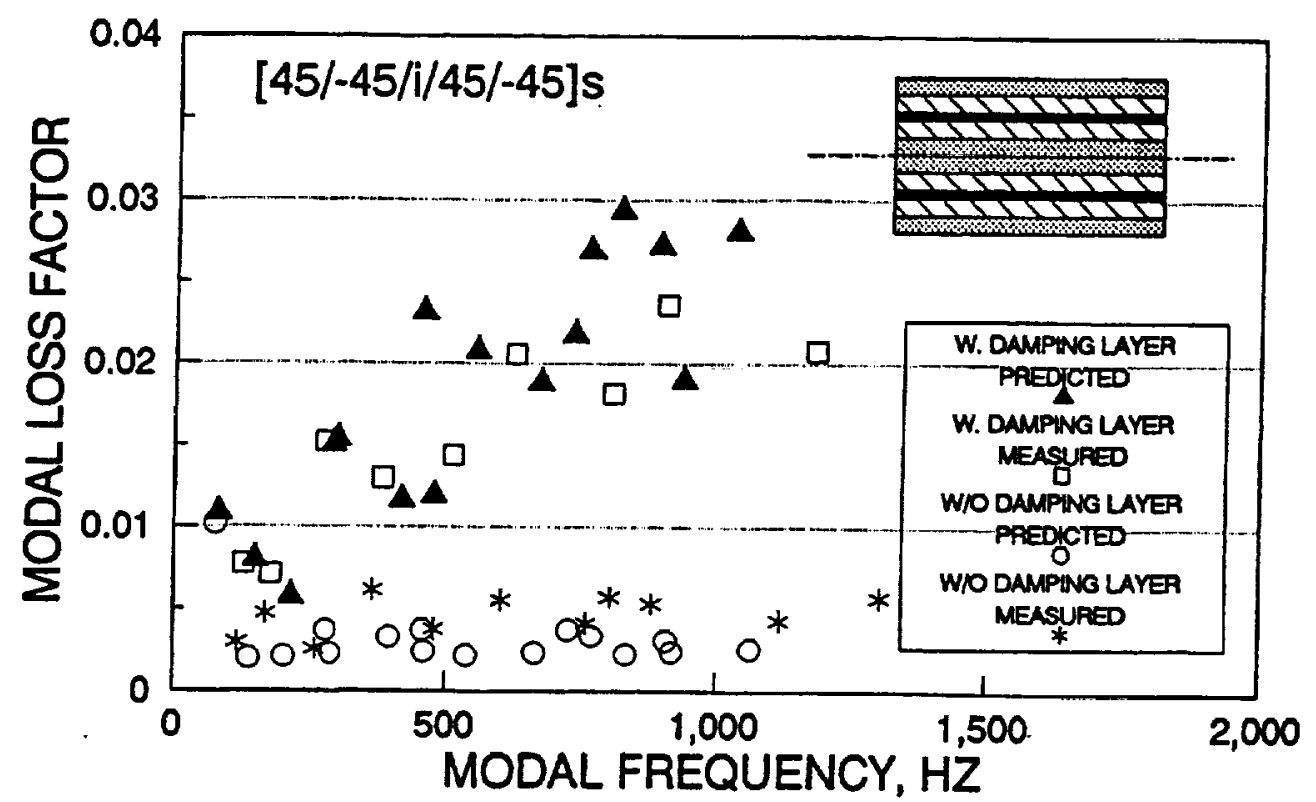

Figure 4 Predicted and measured modal characteristics of a $\left[45_{2} /-45_{2} / 2 / 45_{2} /-45_{2}\right]_{s}$ T300/934 simply supported plate with ISD110 damping layers.

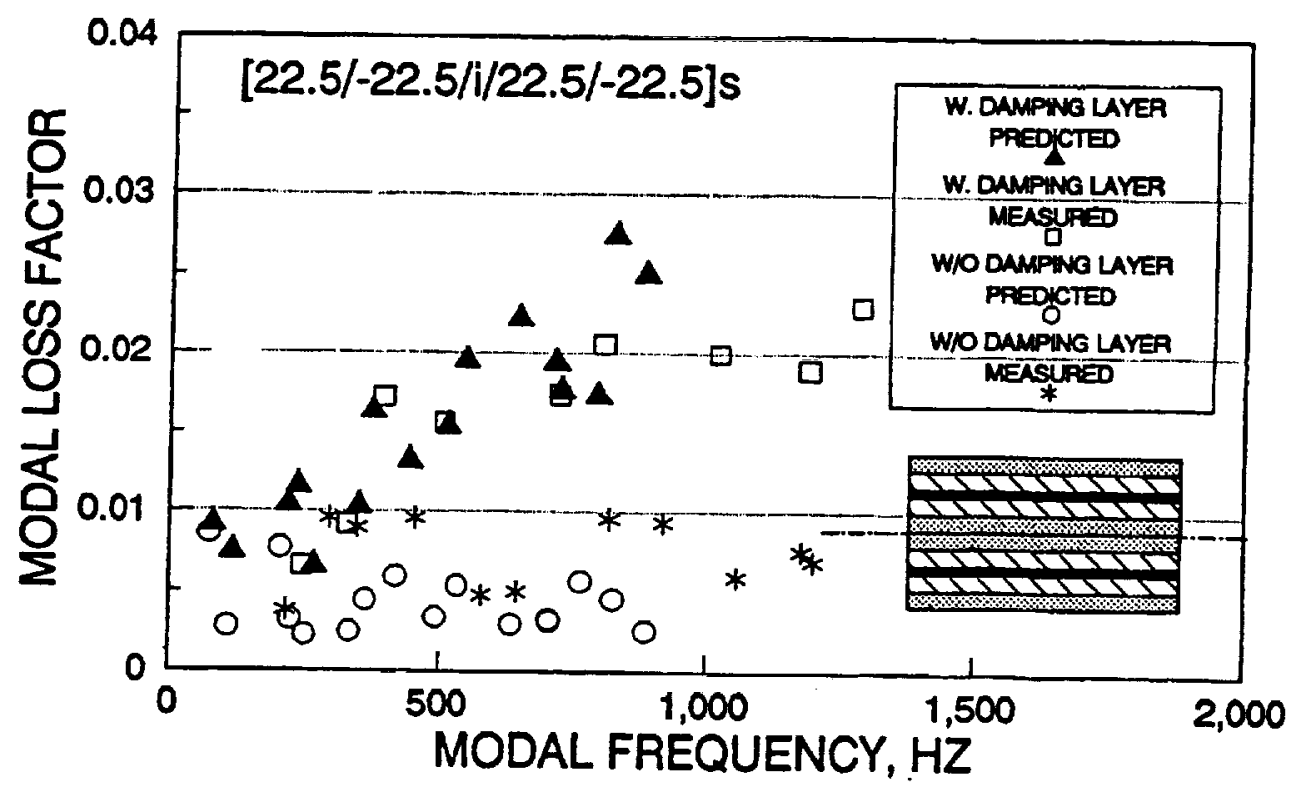

Figure 5 Predicted and measured modal characteristics of a $\left[22.5_{2} /-22.5_{2} / \mathrm{i} / 22.5_{2} /\right.$ $\left.22.5_{2}\right]_{\mathrm{s}}$ T300/934 simply supported plate with ISD110 damping layers. 

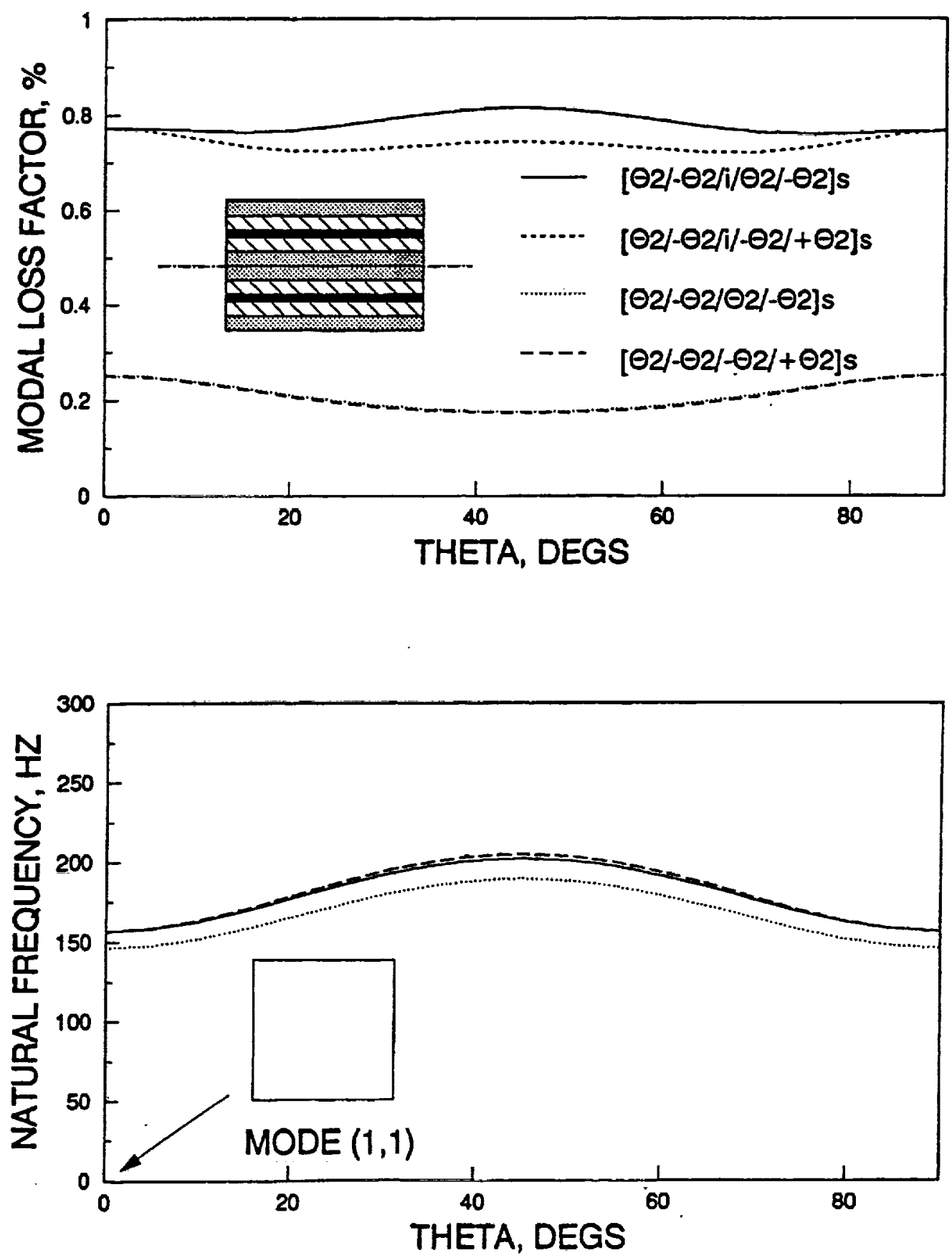

Figure 6 Modal loss factor and natural frequency of angle-ply T300/934 simply supported plates; mode 1. 

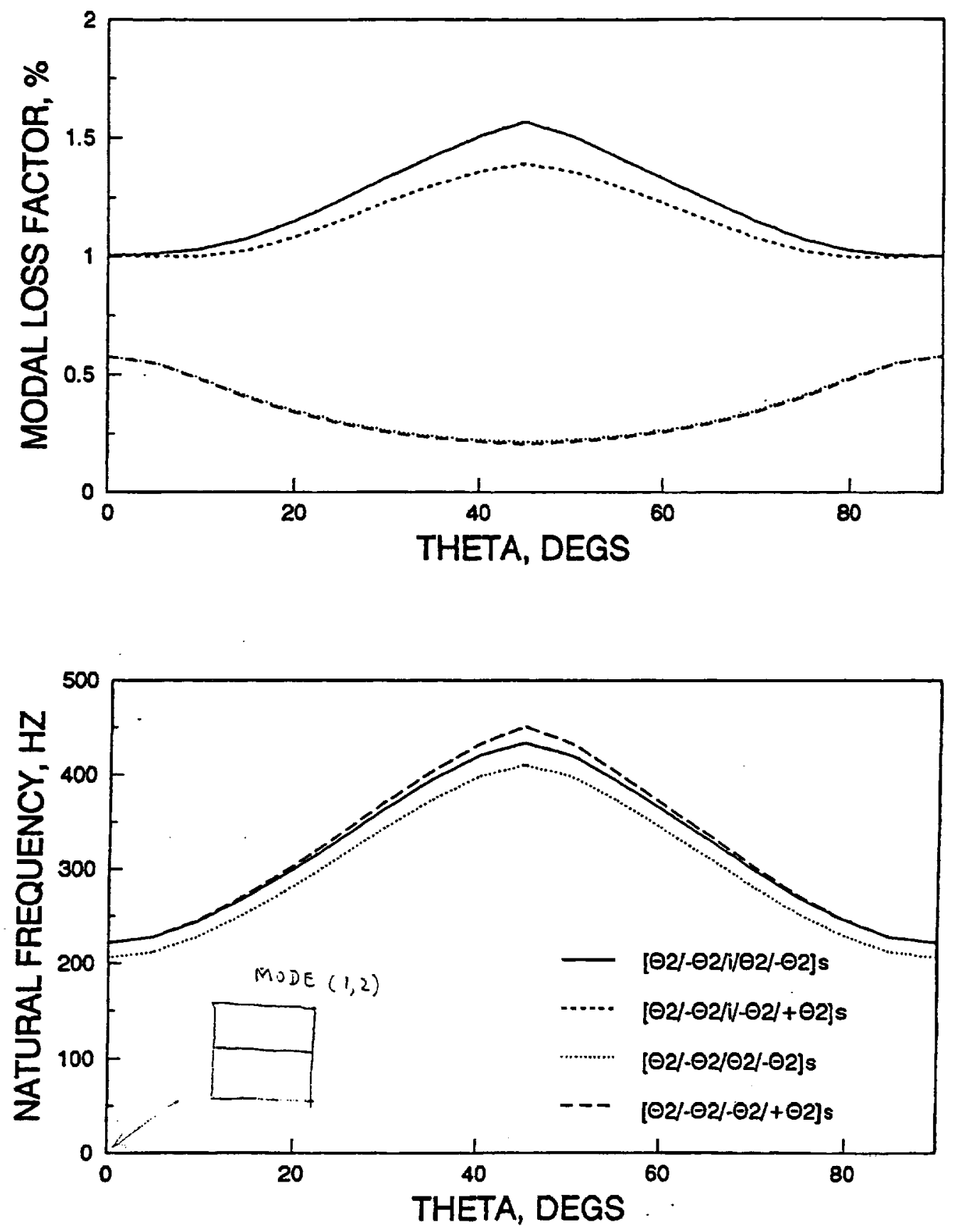

Figure 7 Modal loss factor and natural frequency of angle-ply T300/934 simply supported plates; mode 2. 

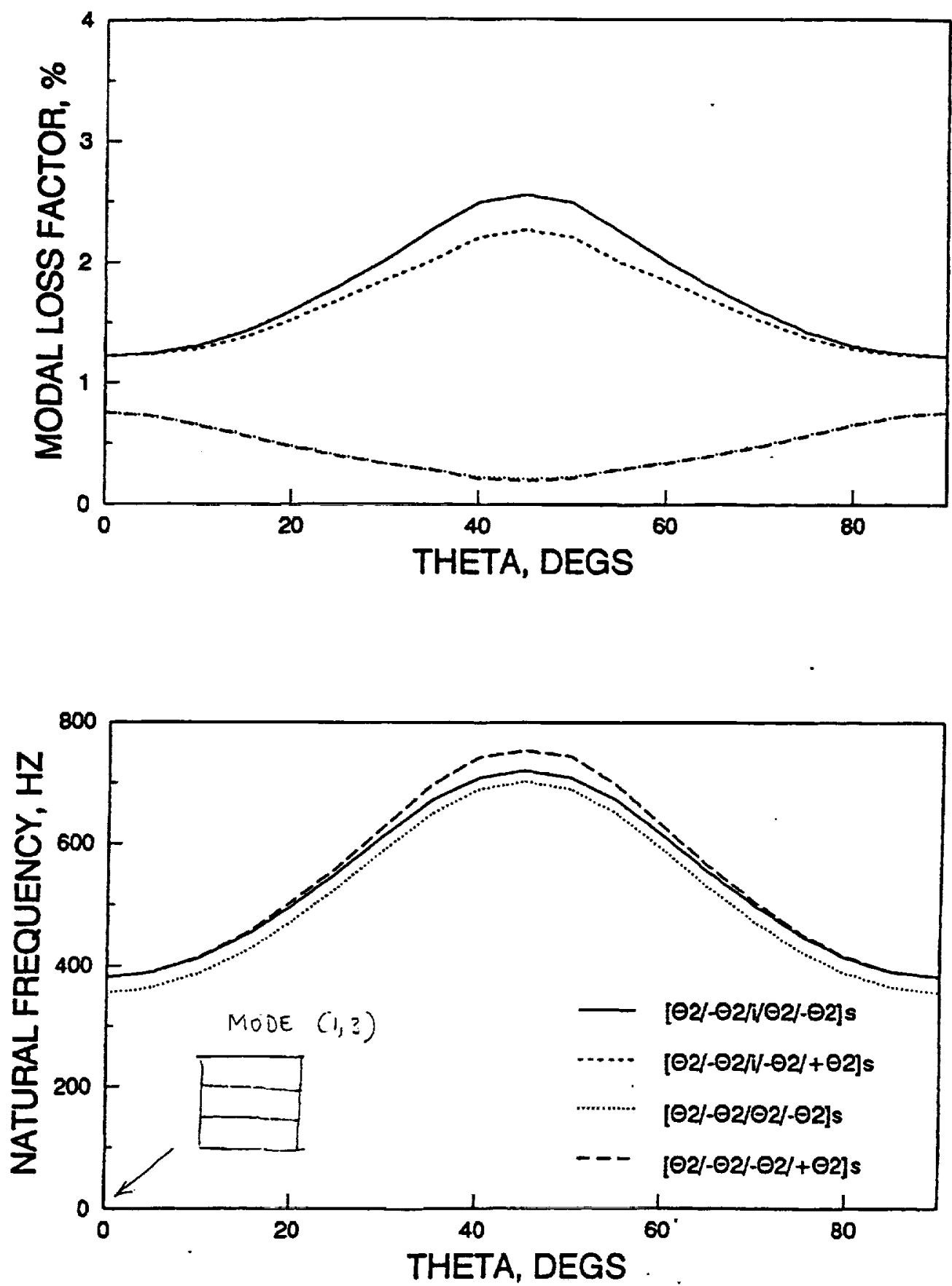

Figure 8 Modal loss factor and natural frequency of angle-ply T300/934 simply supported plates; mode 3. 

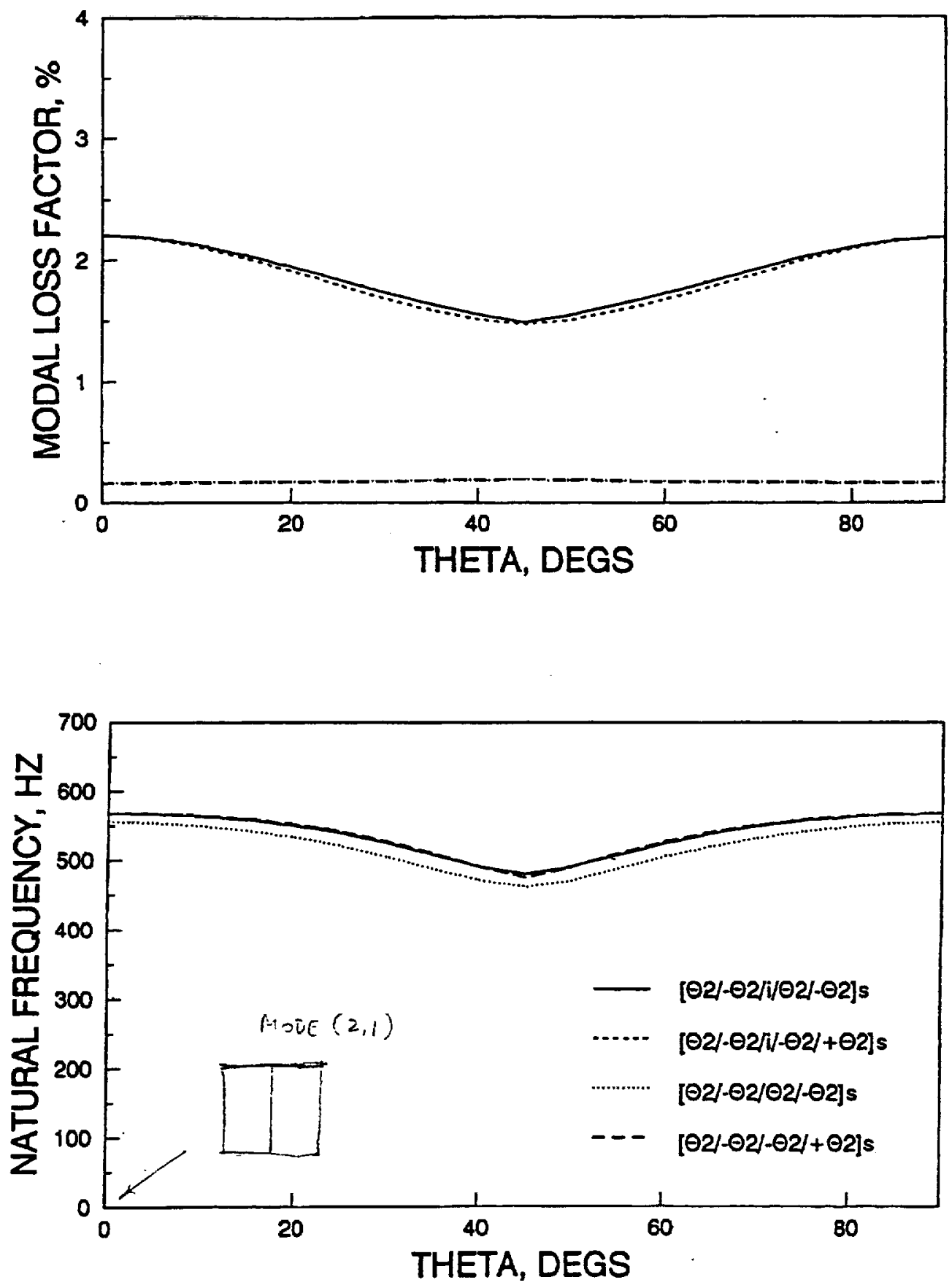

Figure 9 Modal loss factor and natural frequency of angle-ply T300/934 simply supported plates; mode 4. 

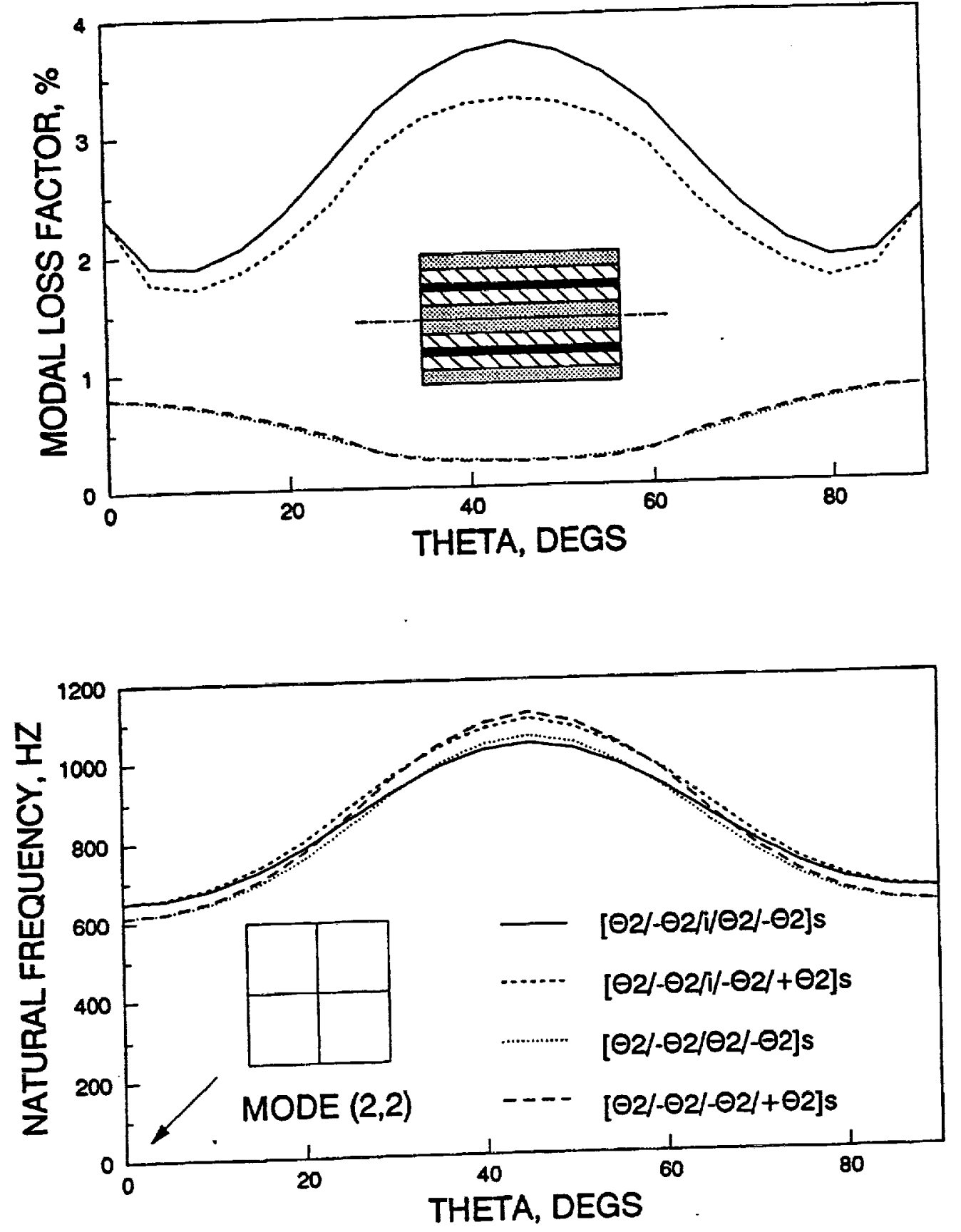

Figure 10 Modal loss factor and natural frequency of angle-ply T300/934 simply supported plates; mode 5 . 
Public reporing burden for this collection of information is estimated to average 1 hour per response, including the time for reviewing instructions, searching existing data sources, Plic gather Davis Highway, Suite 1204, Arlington. VA 22202-4302, and to the Office of Management and Budget, Papenwork Reduction Project (0704-0188), Washington, DC 20503.
1. AGENCY USE ONLY (Leave blank)
2 REPORT DATE
May 1993
3. REPORT TYPE AND DATES COVERED
Technical Memorandum

\section{TITLE AND SUBTITLE}

5. FUNDING NUMBERS

Dynamic Characteristics of Specialty Composite Structures With Embedded

Damping Layers

6. AUTHOR(S)

D.A. Saravanos and C.C. Chamis

WU-510-02-12

7. PERFORMING ORGANZATION NAME(S) AND ADDRESS(ES)

National Aeronautics and Space Administration

Lewis Research Center

Cleveland, Ohio 44135-3191

8. PERFORMING ORGANIZATION

REPORT NUMBER

E-7863

9. SPONSORING/MONITORING AGENCY NAME(S) AND ADDRESS(ES)

10. SPONSORING/MONITORING AGENCY REPORT NUMBER

National Aeronautics and Space Administration

Washington, D.C. 20546-0001

NASA TM-106165

11. SUPPLEMENTAAY NOTES

Prepared for the Symposium on Vibroacoustic Characterization of Materials and Structures sponsored by the American Society of Mechanical Engineers, Anaheim, California, November 8-12, 1992. D.A. Saravanos, Ohio Aerospace Institute, 22800 Cedar Point Road, Brook Park, Ohio 44142, and NASA Resident Research Associate at Lewis Research Center and C.C. Chamis, NASA Lewis Research Center. Responsible person, C.C. Chamis, (216) 433-3252.

12a. DISTRIBUTION/AVAILABILITY STATEMENT

12b. DISTRIBUTION CODE

Unclassified - Unlimited

Subject Category 24

\section{ABSTRACT (Maximum 200 words)}

Damping mechanics for simulating the damped dynamic characteristics in specialty composite structures with compliant interlaminar damping layers are presented. Finite-element based mechanics incorporating a discrete layer (or layer-wise) laminate damping theory are utilized to represent general laminate configurations in terms of lay-up and fiber orientation angles, cross-sectional thickness, shape and boundary conditions. Evaluations of the method with exact solutions and experimental data illustrate the accuracy of the method. Additional applications investigate the potential for significant damping enhancement in angle-ply composite laminates with cocured interlaminar damping layers.

\section{SUBJECT TERMS}

Composites; Damping layers; Compliant layers; Interlaminar; Damping; Structures;

Laminates; Dynamic analysis; Natural frequencies; Interlaminar effects; Finite elements

15. NUMBER OF PAGES

17. SECURTYY CLASSIFICATION OF REPORT

Unclassified
18. SECURITY CLASSIFICATION OF THIS PAGE

Unclassified
19. SECURITY CLASSIFICATION OF ABSTRACT Unclassified 